\title{
Ultralight Biomass Aerogels with Multifunctionality and Superelasticity Under Extreme Conditions
}

Shu-Liang Li, Juan Wang, Hai-Bo Zhao*, Jin-Bo Cheng, Ai-Ning Zhang, Ting Wang, Min Cao, Teng Fu and Yu-Zhong Wang*

The Collaborative Innovation Center for Eco-Friendly and Fire-Safety Polymeric Materials (MoE), National Engineering Laboratory of Eco-Friendly Polymeric Materials (Sichuan), State Key Laboratory of Polymer Materials Engineering, College of Chemistry, Sichuan University, Chengdu 610064, China. 


\section{Table of Content}

S-1. Table of Content

S-2. Table S1. Relative atomic percentages on the surface of the aerogels calculated by EDX.

Figure S1. Morphology and statistic of sizes of aldehyde cellulose nanofibers.

S-3. Figure S2. EDX spectra of GC aerogel and HGC aerogel.

S-4. Figure S3. Thermal gravimetric analysis of GC aerogel and HGC aerogel.

S-5. Figure S4. SEM images for the surface morphologies of GC aerogel and HGC aerogel.

Figure S5. Digital photos of GC aerogel, gelatin aerogel, and cellulose aerogel, respectively before and after aging.

S-6. Figure S6. Digital photos of oil removal processes for kerosene and chloroform using $\mathrm{HGC}$ aerogel at room temperature.

Table S2. Absorption capacity and reusability of oil absorbents developed recently.

S-7.Figure S7. Schematic diagram of the aerogel on a cooling device.

S-8. Figure S8. Absorption capacity of HGC aerogel for kerosene in 10 absorbingsqueezing cycles.

Table S3. Flammability data of HGC aerogel and PU foam from MCC test.

S-9. Figure S9. Device diagram for the test of aerogel compression in liquid nitrogen.

Figure S10. Device diagram for the test of aerogel hiding heat sources.

S-10. References 
Table S1. Relative atomic percentages on the surface of the aerogels calculated by EDX.

\begin{tabular}{ccccccc}
\hline Sample & $\mathrm{C}$ & $\mathrm{N}$ & $\mathrm{O}$ & $\mathrm{Si}$ & $\mathrm{S}$ & $\mathrm{Cl}$ \\
\hline $\begin{array}{c}\text { GC aerogel } \\
(\mathrm{w} \mathrm{t} \%)\end{array}$ & 52.87 & 16.63 & 29.40 & 0.00 & 0.97 & 0.13 \\
$\begin{array}{c}\text { HGC aerogel } \\
(\mathrm{wt} \%)\end{array}$ & 48.74 & 13.98 & 27.31 & 5.16 & 0.95 & 3.86 \\
\hline
\end{tabular}

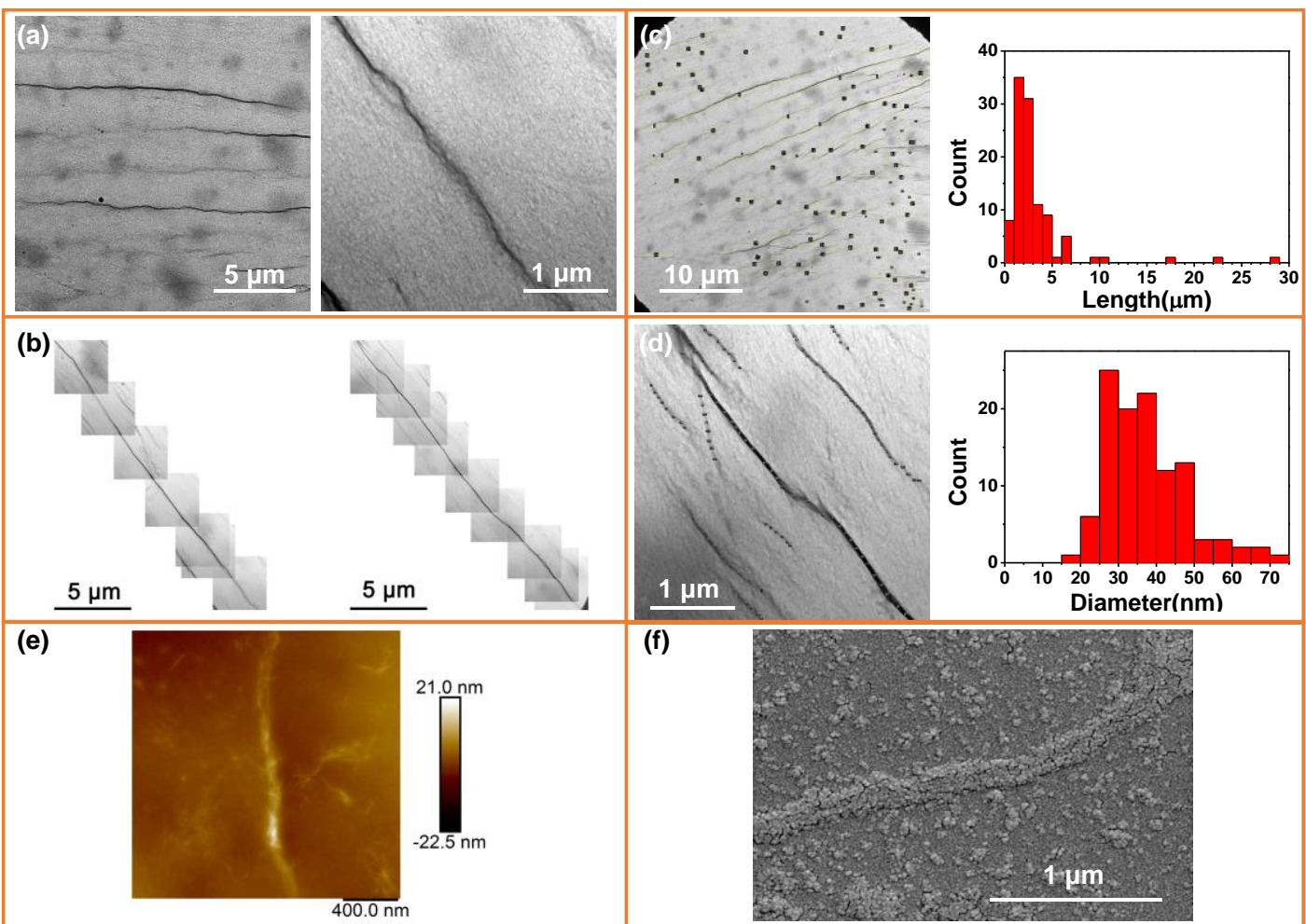

Figure S1. (a) TEM image of the aldehyde cellulose nanofibers. (b) A series of TEM images of a $22 \mu \mathrm{m}$-long and a $23 \mu \mathrm{m}$-long cellulose nanofiber bundles. (c) A statistic of lengths of aldehyde cellulose nanofibers. (d) A statistic of diameters of aldehyde cellulose nanofibers. (e) AFM image of the aldehyde cellulose nanofibers. (f) SEM image of the aldehyde cellulose nanofibers. 
The aldehyde nanocelluloses were well dispersed with diameters in 18-70 nm and their lengths range from $0.5-28 \mu \mathrm{m}$. The means of diameters and lengths were 37.12 $\mathrm{nm}$ and $3.24 \mu \mathrm{m}$, separately.
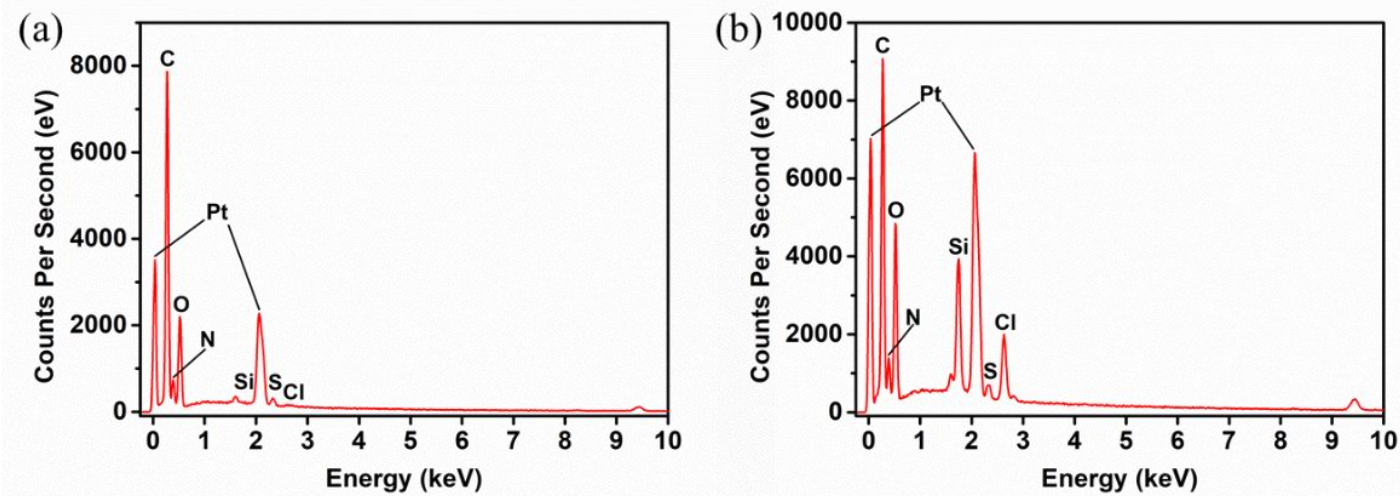

Figure S2. EDX spectra of (a) GC aerogel and (b) HGC aerogel.

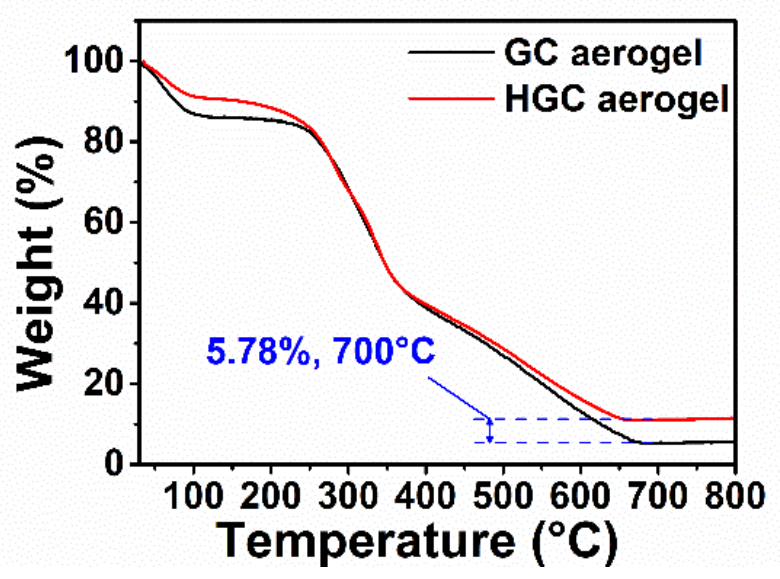

Figure S3. Thermal gravimetric analys is of GC aerogel and HGC aerogel.

The content of Si was 5.16wt\% in EDX analysis results (Figure S1). However, in the thermal gravimetric analysis, the residual mass of HGC mainly consisting of silicon 
dioxide was $5.78 \mathrm{wt} \%$ in the air at $800^{\circ} \mathrm{C}$. Based on relative molecular weight, the mass percent of silicon was just $2.70 \mathrm{wt} \%$ in TGA, much lower than the result of EDX. It was indicated that the siloxane occupied a very low content and distributed on the surface but inner. As a result, the silicon has a limited impact on the biodegradation of internal substrates.
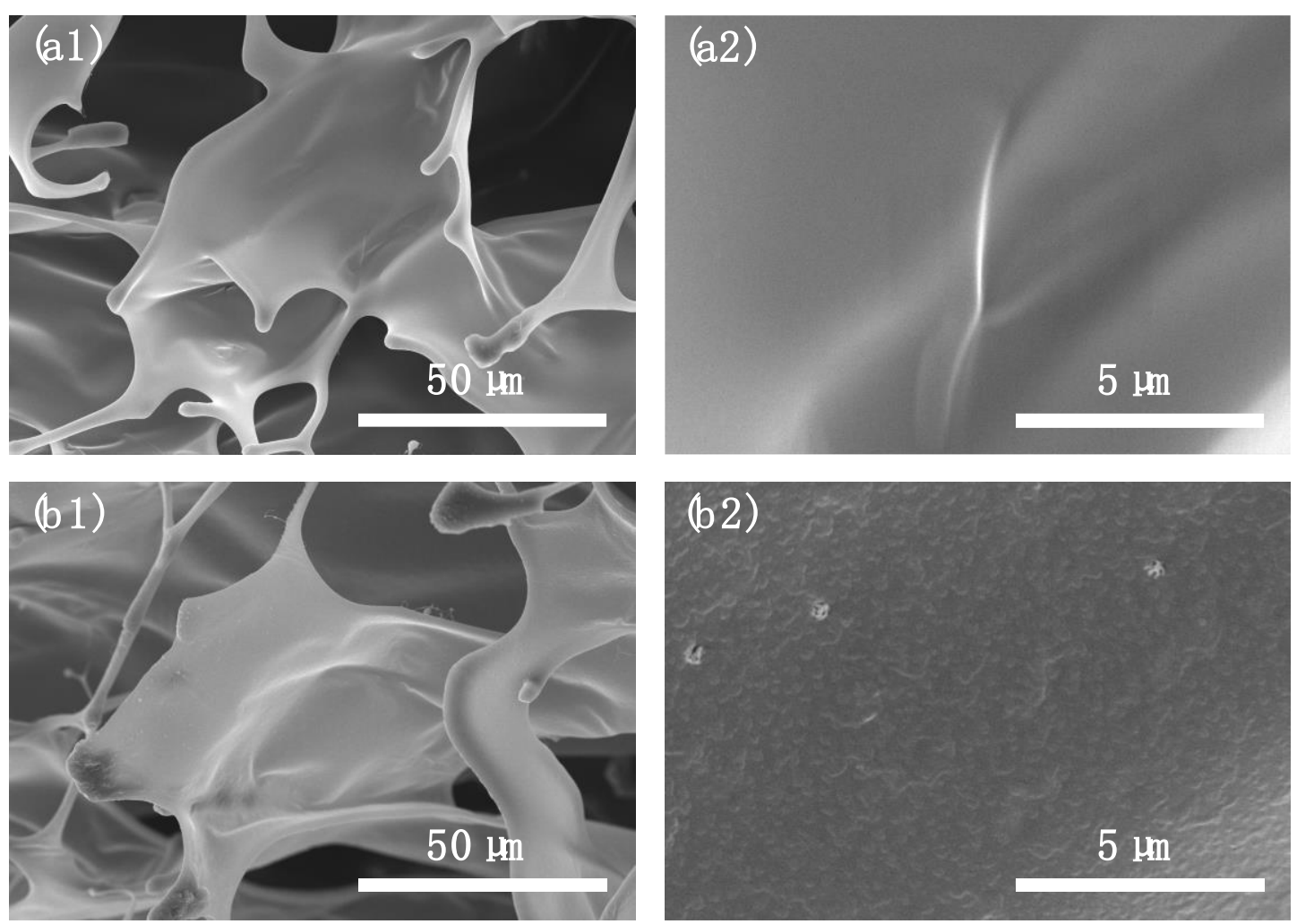

Figure S4. SEM images for the surface morphologies of (a1, a2) GC aerogel and (b1, b2) HGC aerogel. 

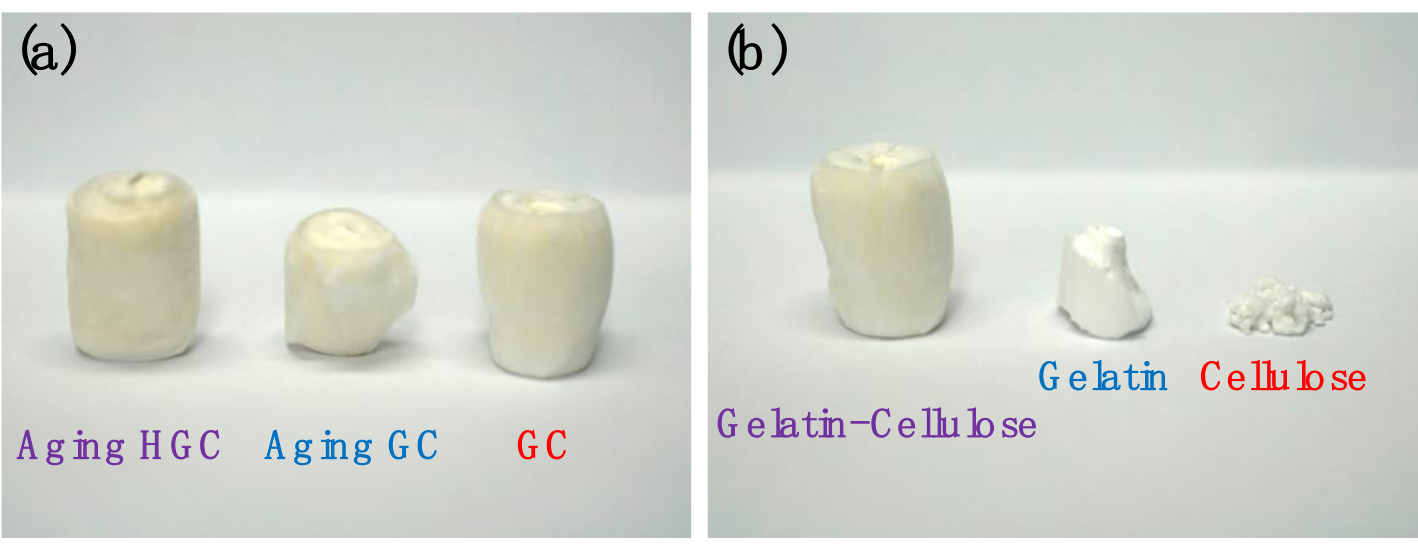

Figure S5. (a) Digital photos of fresh GC aerogel, GC aerogel after aging 7 days and HGC aerogel after aging 2 months. (b) Digital photos of GC aerogel, gelatin aerogel, and cellulose aerogel, respectively.

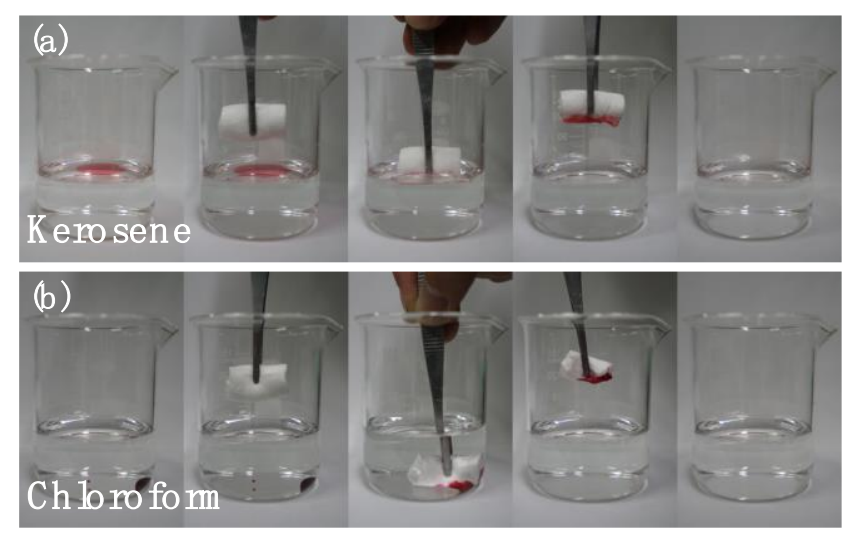

Figure S6. Digital photos of oil removal processes for (a) kerosene and (b) chloroform using $\mathrm{HGC}$ aerogel at room temperature.

Table S2. Absorption capacity and reusability of oil absorbents developed recently.

\begin{tabular}{cccc}
\hline Materials & Author & Adsorption Capacity $(\mathrm{g} / \mathrm{g})$ & Cycles \\
\hline Polyurethane Sponge & Cao et al. $^{1}$ & 3.75 & 10 \\
Melamine Sponge & Feng et al. $^{2}$ & 75 & 10 \\
PLA Nonw oven Fabric & Gu et al. $^{3}$ & 27 (conversion) & 10 \\
Carbon Aerogels & Haiyan et al. $^{4}$ & 220 & 10 \\
\hline
\end{tabular}




\begin{tabular}{|c|c|c|c|}
\hline Biomass Aerogel & Jiang et al. ${ }^{5}$ & 12 & 10 \\
\hline Graphene-carbon Nanotube Aerogels & Kabiri et al. ${ }^{6}$ & 32 (conversion) & 6 \\
\hline Superhydrophobic Sponge & Liu et al. ${ }^{7}$ & 29 & 10 \\
\hline Melamine Sponge & Meng et al. ${ }^{8}$ & 87 & 6 \\
\hline Graphene-based Sponges & Nguyen et al. ${ }^{9}$ & 55 & 5 \\
\hline Polyurethane/Graphene Oxide & Oribayo et al. ${ }^{10}$ & 32 & 20 \\
\hline Melamine Foam & Song et al. ${ }^{11}$ & 56 & 20 \\
\hline Graphene-carbon Nanotube Aerogel & Wan et al. ${ }^{12}$ & 115 & 7 \\
\hline Carbon Aerogels & Wu et al. ${ }^{13}$ & 108 & 5 \\
\hline Melamine Sponge & Yao et al. ${ }^{14}$ & 87 (conversion) & 6 \\
\hline Porous PDMS & Yu et al. ${ }^{15}$ & 6.8 & 25 \\
\hline Silica Nanocomposite Particles & Yu et al. ${ }^{16}$ & 3.5 & 20 \\
\hline Superhydrophobic Sponges & Zhang et al. ${ }^{17}$ & 29 & 10 \\
\hline Carbon Aerogels & Zhao et al. ${ }^{18}$ & 210 & 1 \\
\hline Calotropis Gigantea Fiber & Zheng et al. ${ }^{19}$ & 23 & 10 \\
\hline Carbon Aerogels & Xiao et al. ${ }^{20}$ & 237 & 10 \\
\hline Fiber & Zhang et al. ${ }^{21}$ & 26 & 10 \\
\hline Fiber & Gao et al. ${ }^{22}$ & 25 & 10 \\
\hline Biomass Foam & Wang et al. ${ }^{23}$ & 11 & 10 \\
\hline Carbon Aerogels & Rahmani et al. ${ }^{24}$ & 160 (conversion) & 10 \\
\hline Carbon Foam & Xu et al. ${ }^{25}$ & 94 (conversion) & 10 \\
\hline Carbon Foam & Lv et al. ${ }^{26}$ & 35 (conversion) & 10 \\
\hline
\end{tabular}

※The adsorption capacities were based on the adsorption for $n$-hexane. Some data marked with "conversion" were calculated from toluene absorption capacities based on density.

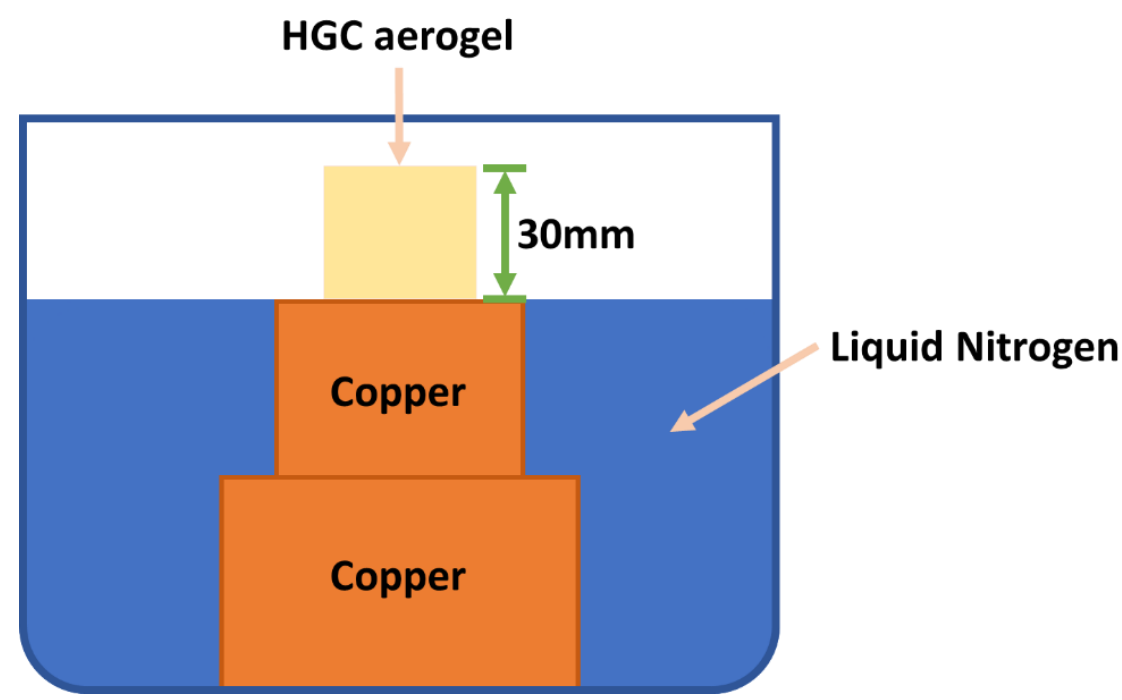

Figure S7. Schematic diagram of the aerogel on a cooling device. 


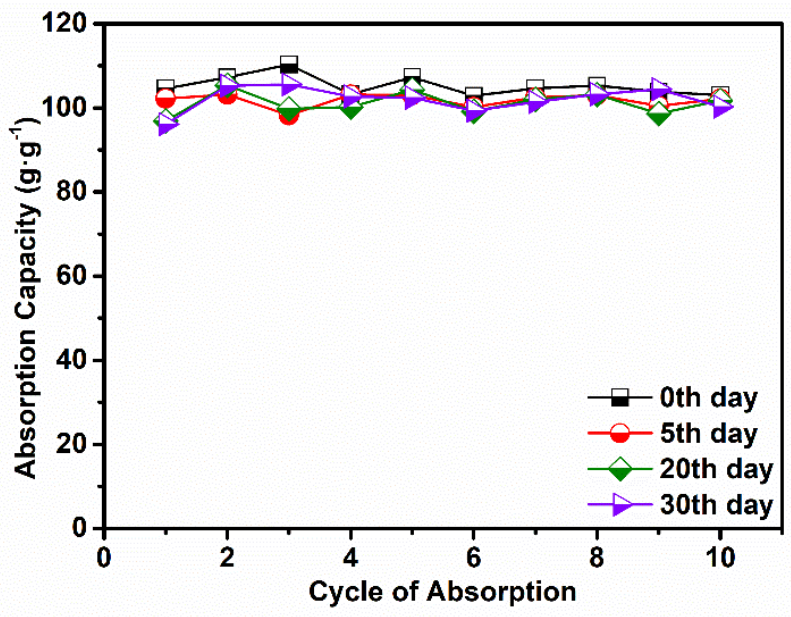

Figure S8. Absorption capacity of HGC aerogel for kerosene in 10 absorbingsqueezing cycles.

Table S3. Flammability data of HGC aerogel and PU foam from MCC test.

\begin{tabular}{cccc}
\hline Sample & HRC $(\mathrm{J} / \mathrm{g} \cdot \mathrm{K})$ & Peak HRR $(\mathrm{W} / \mathrm{g})$ & Total HR $(\mathrm{kJ} / \mathrm{g})$ \\
\hline HGC & 168 & 169.4 & 19.8 \\
PU & 829 & 970.7 & 43.8 \\
\hline
\end{tabular}




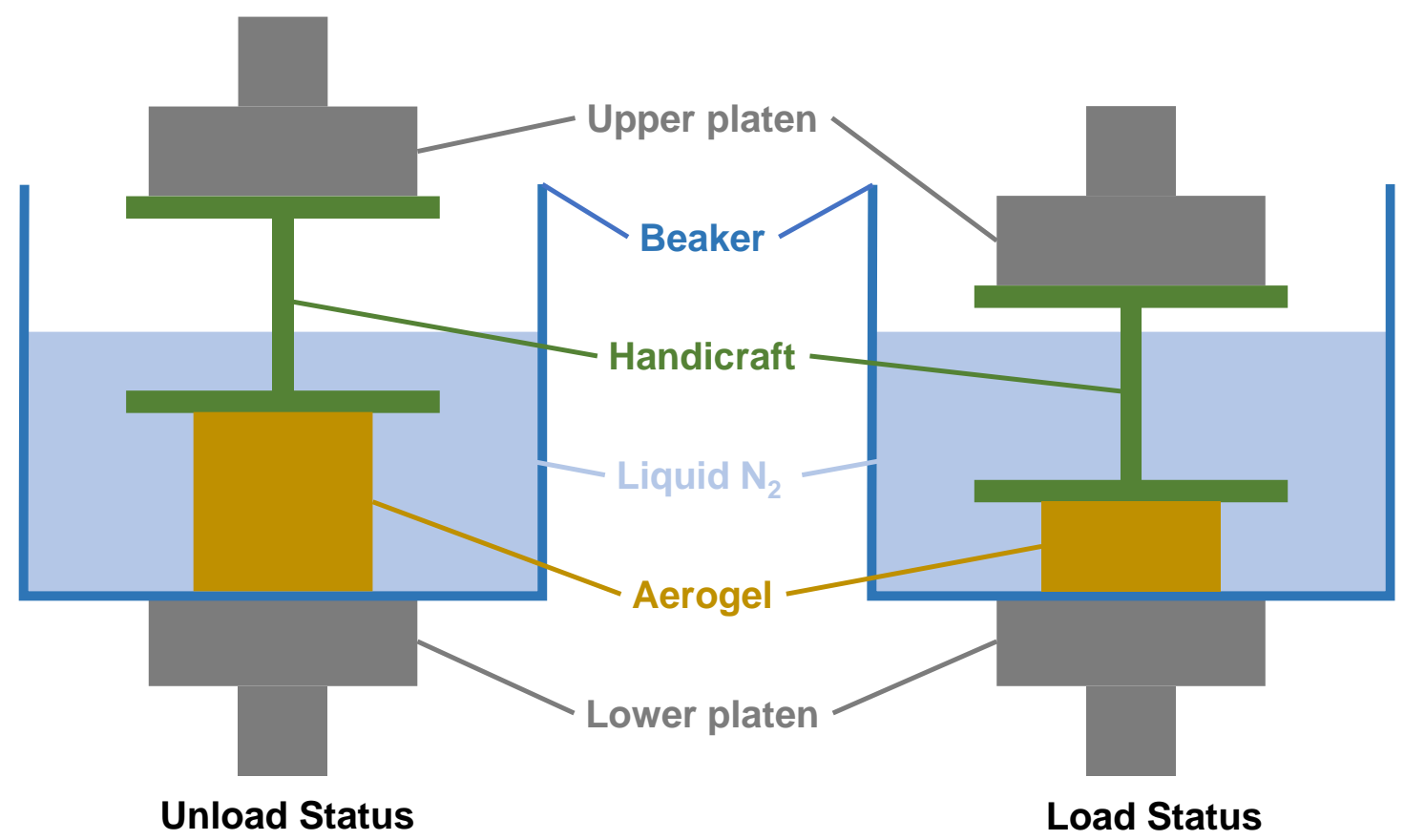

Figure S9. Device diagram for the test of aerogel compression in liquid nitrogen.

The compression test in liquid nitrogen. First, zero the load with the lower piece of handicraft soaked in liquid nitrogen. Then, put the aerogel in liquid nitrogen, and make it sandwiched between the handicraft and the bottom of the beaker. Aerogel samples were compressed in $50 \%$ specific strain at a rate of $50 \mathrm{~mm} / \mathrm{min}$.

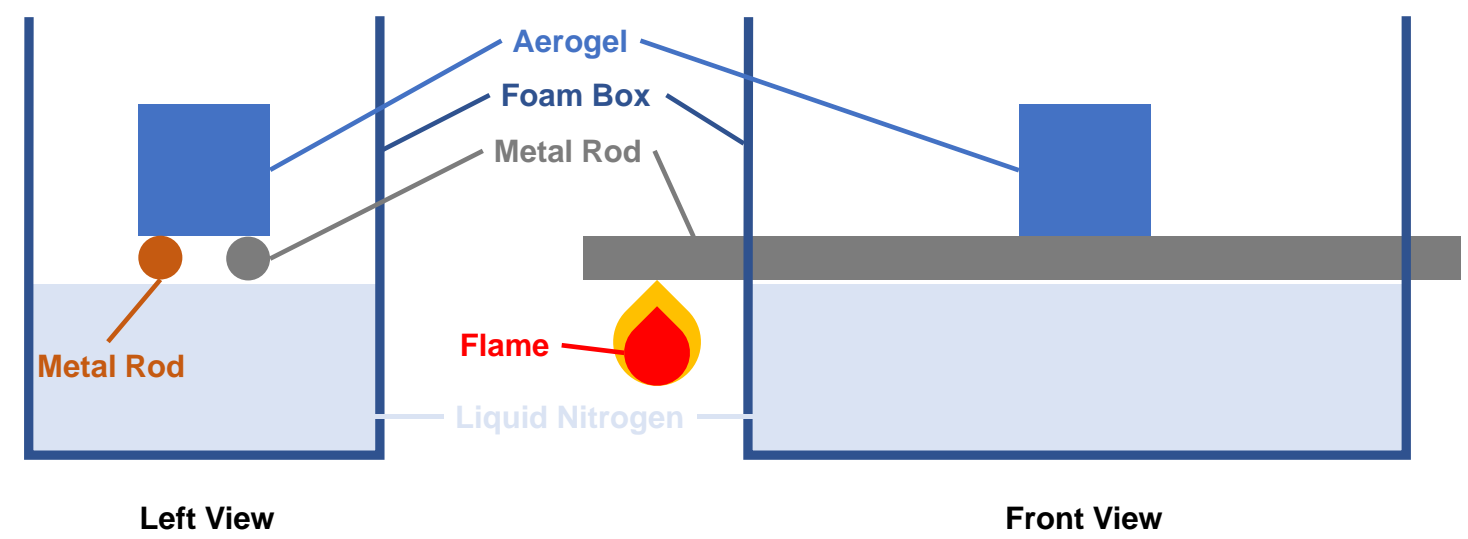

Figure S10. Device diagram for the test of aerogel hiding heat sources. 


\section{References}

1. Cao, N.; Yang, B.; Barras, A.; Szunerits, S.; Boukherroub, R., Polyurethane Sponge Functionalized with Superhydrophobic Nanodiamond Particles for Efficient Oil/Water Separation. Chem. Eng. J. 2017, 307, 319-325.

2. Feng, Y.; Wang, Y.; Wang, Y.; Yao, J.; Feng, Y.; Wang, Y.; Wang, Y.; Yao, J., Furfuryl alcohol modified melamine sponge for high-efficient oil spill clean-up and recovery. J. Mater. Chem. A 2017, 5. 3. Gu, J.; Xiao, P.; Chen, P.; Zhang, L.; Wang, H.; Dai, L.; Song, L.; Huang, Y.; Zhang, J.; Chen, T., Functionalization of Biodegradable PLA Nonwoven Fabric as Superoleophilic and Superhydrophobic Material for Efficient Oil Absorption and Oil/Water Separation. ACS Appl. Mater. Interfaces 2017, 9, 5968.

4. Haiyan, S.; Zhen, X.; Chao, G., Multifunctional, ultra-flyweight, synergistically as sembled carbon aerogels. Adv. Mater. 2013, 25, 2554-2560.

5. Jiang, J. X.; Zhang, Q. H.; Zhan, X. L.; Chen, F. Q., Renewable, Biomass -Derived, Honeycomblike Aerogel As a Robust Oil Absorbent with Two-Way Reusability. ACS Sustainable Chem. Eng. 2017, 5, 10307-10316.

6. Kabiri, S.; Tran, D. N. H.; Altalhi, T.; Losic, D., Outstanding adsorption performance of graphenecarbon nanotube aerogels for continuous oil removal. Carbon N Y 2014, 80, 523-533.

7. Liu, Q.; Meng, K.; Ding, K.; Wang, Y., A Superhydrophobic Sponge with Hierarchical Structure as an Efficient and Recyclable Oil Absorbent. Chempluschem 2015, 80, 1435-1439.

8. $\quad$ Meng, G.; Peng, H.; Wu, J.; Wang, Y.; Wang, H.; Liu, Z.; Guo, X., Fabrication of superhydrophobic cellulose/chitos an composite aerogel for oil/water separation. Fibers \& Polym. 2017, 18, 706-712.

9. Nguyen, D. D.; Tai, N. H.; Lee, S. B.; Kuo, W. S., Superhydrophobic and superoleophilic properties of graphene-based sponges fabricated using a facile dip coating method. Energy \& Environ. Sci. 2012, 5, 7908-7912.

10. Oribayo, O.; Feng, X.; Rempel, G. L.; Pan, Q., Synthesis of lignin-based polyurethane/graphene oxide foam and its application as an absorbent for oil spill clean-ups and recovery. Chem. Eng. J. 2017, 323.

11. Song, S.; Yang, H.; Su, C.; Jiang, Z.; Lu, Z., Ultrasonic-microwave assisted synthesis of stable reduced graphene oxide modified melamine foam with superhydrophobicity and high oil adsorption capacities. Chem. Eng. J. 2016, 306, 504-511.

12. Wan, W.; Zhang, R.; Li, W.; Liu, H.; Lin, Y.; Li, L.; Zhou, Y., Graphene-carbon nanotube aerogel as an ultra-light, compressible and recyclable highly efficient absorbent for oil and dyes. Environ. Sci. Nano 2016, 3, 107-113.

13. Wu, Z. Y.; Li, C.; Liang, H. W.; Chen, J. F.; Yu, S. H., Ultralight, flexible, and fire $\square$ resistant carbon nanofiber aerogels from bacterial cellulose. Angew. Chem. 2013, 125, 2997-3001.

14. Yao, Q.; Zhao, P.; Li, R.; Li, C.; Luo, Y.; Zhou, G.; Yang, M., Fabrication of recyclable carbonized asphalt-melamine sponges with high oil-absorption capability. J. Chem. Technol. Biotechnol. 2017, 92, 1415-1420.

15. Yu, C.; Yu, C.; Cui, L.; Song, Z.; Zhao, X.; Ma, Y.; Jiang, L., Facile Preparation of the Porous PDMS Oil-Absorbent for Oil/Water Separation. Adv. Mater. Interfaces 2017, 4.

16. Yu, L.; Hao, G.; Liang, Q.; Zhou, S.; Zhang, N.; Wei, J., Facile preparation and characterization of modified magnetic silica nanocomposite particles for oil absorption. Appl. Surf. Sci. 2015, 357, $2297-$ 
2305.

17. Zhang, L.; Li, H.; Lai, X.; Su, X.; Liang, T.; Zeng, X., Thiolated graphene-based superhydrophobic sponges for oil-water separation. Chem. Eng. J. 2017, 316, 736-743.

18. Zhao, Y.; Hu, C.; Hu, Y.; Cheng, H.; Shi, G.; Qu, L., A versatile, ultralight, nitrogen $\square$ doped graphene framework. Angew. Chem., Int. Ed. 2012, 51, 11371-11375.

19. Zheng, Y.; Zhu, Y.; Wang, A.; Hu, H., Potential of Calotropis gigantea fiber as an absorbent for removal of oil from water. Ind. Crop. Prod. 2016, 83, 387-390.

20. Xiao, J.; Lv, W.; Song, Y.; Qiang, Z., Graphene/Nanofiber Aerogels: Performance Regulation towards Multiple Applications in Dye Adsorption and Oil/water Separation. Chem. Eng. J. 2018, 338, S1385894717322787.

21. Zhang, D.; Jin, X.-Z.; Huang, T.; Zhang, N.; Qi, X.-d.; Yang, J.-h.; Zhou, Z.-w.; Wang, Y., Electrospun Fibrous Membranes with Dual-Scaled Porous Structure: Super Hydrophobicity, Super Lipophilicity, Excellent Water Adhesion, and Anti-Icing for Highly Efficient Oil Adsorption/Separation. ACS Appl. Mater. Interfaces 2019, 11, 5073-5083.

22. Gao, J.; Xin, S.; Huang, X.; Ling, W.; Bei, L.; Xue, H., Facile preparation of polymer microspheres and fibers with a hollow core and porous shell for oil adsorption and oil/water separation. Appl. Surf. Sci. 2018, 439.

23. Wang, Y.; Feng, Y.; Yao, J., Construction of hydrophobic alginate-based foams induced by zirconium ions for oil and organic solvent cleanup. J. Colloid Interf. Sci. 2019, 533, 182-189.

24. Rahmani, Z.; Rashidi, A. M.; Samadi, M. T.; Rahmani, A. R., N-doped reduced graphene oxide aerogel for the selective adsorption of oil pollutants from water: Isotherm and kinetic study. J. Ind. Eng. Chem. 2018, 61, 416-426.

25. Xu, Y.; Zhang, Z.; Geng, X.; Jin, J.; Iqbal, M.; Han, A.; Ding, B.; Liu, J., Smart carbon foams with switchable wettability for fast oil recovery. Carbon 2019, 149, 242-247.

26. Lv, X.; Tian, D.; Peng, Y; Li, J.; Jiang, G., Superhydrophobic magnetic reduced graphene oxide decorated foam for efficient and repeatable oil-water separation. Appl. Surf. Sci. 2019, 466, 937-945. 